\title{
Formulation and Receiving Power Cookies Hayakarah as an Effort to Prevent Anemia
}

\author{
$1^{\text {st }}$ Podojoyo Podojoyo \\ Department of Nutrition \\ Poltekkes Palembang, \\ Palembang Indonesia \\ podojoyo@poltekkespalembang.ac.id \\ $4^{\text {th }}$ Tri Friantin \\ Department of Nutrition, \\ Poltekkes Palembang, \\ Palembang Indonesia \\ trifriantini77@gmail.com
}

\author{
$2^{\text {nd }}$ Budi Yulianto Surname line \\ Department of Nutrition \\ Poltekkes Palembang \\ Palembang Indonesia \\ budiyuliant0@poltekkespalembang.ac.id
}

\author{
$3^{\text {rd }}$ Annisa Silvia Ningsih \\ Department of Nutrition \\ Poltekkes Palembang, \\ Palembang Indonesia \\ annisasilvi@poltekkespalembang.ac.id
}

corresponding Author: podojoyo@ poltekkespalembang.ac.id

\begin{abstract}
Iron deficiency anemia is a micronutrition problem in Indonesia, as much as $84.6 \%$ occurs in the group of pregnant women aged 15-24 years. One of the issues of iron deficiency anemia is to provide foods high in protein and iron in the form of cookies. This research aims to obtain a formula of cookies derived from the foodstuff of red beans and chicken liver. Cookies made from chicken liver flour and red bean flour (Phaseolus vulgaris) are named Cookies Hayakarah. This study was experimental using a non-factorial Complete Randomized Design (RAL) of 3 formulas. The results of this study conducted organoleptic tests using semi- trained panellists as many as 25 people. Harakayah cookies organoleptic receiving power test results are obtained in formula 1 with the composition of chicken liver flour and red bean flour in grams (10:20) getting the highest value than a formula 2 and formula 3. Organoleptic test receiving results based on aroma parameters $(\mathbf{7 7 . 6 \%})$, taste $(84.8 \%)$, texture $(85.6 \%)$. The conclusion of the study results is that formula 1 is Hayakarah cookies are highly flavored by panellists based on the taste and texture of organoleptic test results.
\end{abstract}

Keywords: Formulations of cookies, red beans, chicken liver, anemia.

\section{INTRODUCTION}

Nutrition problems in Indonesia are not only caused by micronutrient deficiencies but are also caused by micronutrient deficiencies. Iron deficiency anemia is a micronutrition problem in Indonesia, as much as 84.6
$\%$ occurs in the group of pregnant women aged 15-24 years [1] Anemia caused by iron deficiency resulting in a decrease in the number of red blood cells [2].

Anemia can be caused by several factors, including The iron content of food consumed is insufficient, increasing the body's need for iron, increased expenditure of iron from the body, absorption of iron from food is very low, the presence of substances that inhibit the absorption of substances iron, the presence of parasites in the body such as hookworms or tapeworms, or loss of blood due to accidents or operations, nutritional deficiencies such as intake of folic acid and vitamins A, B12, and C [3], [4].

Women tend to have lower iron stores than men, so women are more susceptible to iron deficiency. If too little iron is consumed or food interacts with limiting the absorption needed by the body to meet iron needs, iron reserves in the body will be used, and this will cause iron deficiency [3].

One strategy to overcome iron anemia is by providing foods that are high in protein and iron. Examples of foods that can be used as iron deficiency include chicken liver. Chicken liver is one of the animal food sources containing iron in the form of ferric $(\mathrm{Fe} 3+)$ which can be absorbed directly by the body without being influenced by inhibiting agents (Health Link BC, 2014). In addition to the use of chicken liver research also added red beans, which are known sources of vegetable protein. Red beans are also rich in 
carbohydrates, minerals and vitamin B. Red beans are also a precursor of vitamin A because they contain carotene. In addition to reducing dependence on flour, flour is replaced with tapioca in this study, so that the utilization of local food is increased.

One way to prevent and overcome anemia is to provide additional food in the form of snacks that are high in protein and iron. A snack that can be consumed is cookies. Based on food statistical data in 2017, the average Indonesian consumption of food per capita cookies from 2014-2017 is $16.8 \mathrm{~g}, 35.3 \mathrm{~g}, 37.3,38.4 \mathrm{~g}$ (cap/week). Within 4 years, there has been an increase in the consumption of Indonesian cookies.

\section{METHOD}

This research uses a Non-Factorial Complete Randomized Design. The study uses 3 (three) kinds of main ingredients used as formulas in research. The formula used with composition: chicken liver flour: red bean flour in gram weight. Formula 1 (10:20); formula 2 (10:10); formula $3(20: 10)$. Other additives are given the same weight for each composition.

\section{A. Material Preparation}

Chicken liver flour is made by washing the chicken liver thoroughly and then steaming after being cooked thinly sliced and then dried using an oven with a temperature of $70{ }^{\circ} \mathrm{C}$ for 3 hours. After drying, the chicken liver is blended until smooth, then sieved with a 60 mesh sieve.

Red bean flour is made by way of dried red beans washed and then steamed. After cooking, it is dried in the oven at $70^{\circ} \mathrm{C}$ for 4 hours. After drying, blend until smooth and then sifted with a 60 mesh sieve

\section{B. Making process}

Cookies are made with 3 (three) formulas with a ratio of chicken liver flour and red beans (10:20; 10:10; 20:10). Other ingredients such as tapioca flour, refined palm sugar, margarine, egg yolks, and choco-chip are the same. All the ingredients are stirred together then printed and then baked in an oven at $150{ }^{\circ} \mathrm{C}$ for 20 minutes or until cooked. The acceptance test uses a hedonic test with trained panellists as many as 25 people.

\section{RESULT}

The determination of the formula for cookies is following the Indonesian Food Composition Table (TKPI) standard, carried out intending to get the best formula in making cookies that will be used as a reference in conducting research. Determination of the amount of chicken liver and red beans flour aims to maximize the substitution of chicken liver and red beans flour in cookies accepted by panellists based on hedonic tests including colour, aroma, taste, and texture in cookies. Treatment of the proportion of tapioca flour, chicken liver and red beans with various formulas until finding 3 formulas with organoleptic which according to the researchers can be accepted and according to the standard nutritional composition of cookies.

\section{The results of the colour assessment of chicken liver and red bean cookies}

Attractive colour cookies can affect a person's acceptability of food [5] The appearance of cookies with colour should be familiar (SNI 01-2973-1992), which means it is not conspicuous because it uses dangerous colour material.

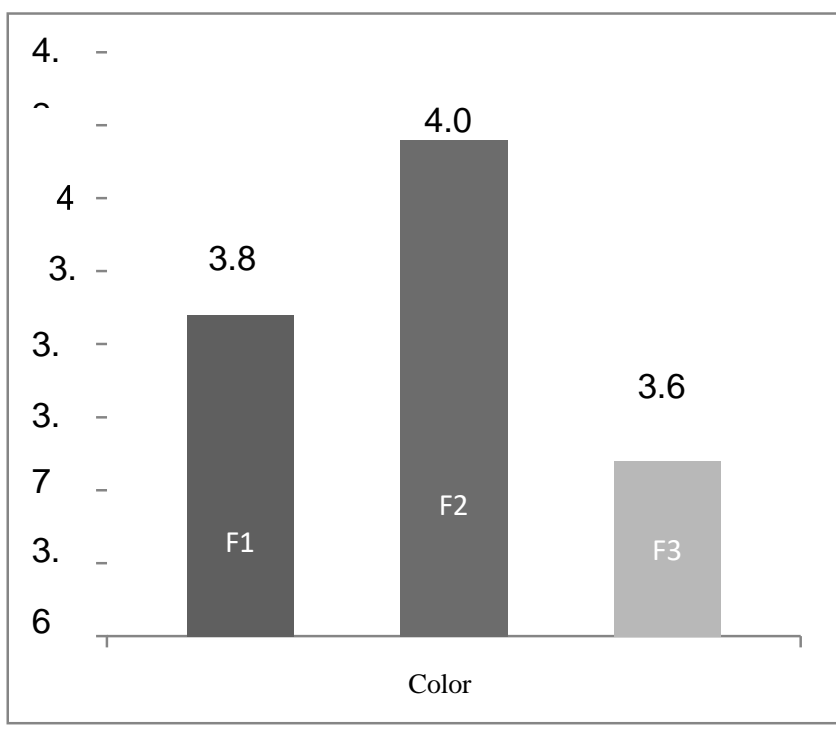

Figure 1. Results of the color assessment of chicken liver and red bean cookies

Figure 1 shows that the average value given to panellists is $3.64-4.08$, the range of likes, likes, and likes. Chicken liver and red bean cookies have the highest value in formula 2 with a value of 4.08 and formula 1 with a value of 3.84 and the lowest average value found in formula 3 with a value of 3.64.

Formula 2 is the panellists most preferred cookie judging from the colour parameters; this is because formula 2 has a more attractive appearance and colour that is brown.

According to research conducted by Putri (2012) on nutrient-rich cookies as an additional food to overcome anemia in pregnant women shows that the most preferred panellists are nutrient-rich cookies with an 
attractive appearance and colour that is chocolate with a sprinkling of choco-chip on it [6].

Allegedly the colour that occurs in making cookies because of the Maillard process. The heating process has opened up the playful side of amino acids in the flour protein and reacts with the reducing sugar component. The reaction will end with the formation of brownish pigment (melanoid).

Based on the results of the colour assessment of chicken liver and red bean cookies Among the three formulas, the closest to the criteria is F2 with an average value of 4.08. Define abbreviations and acronyms the first time they are used in the text, even after being defined in the abstract. Abbreviations such as IEEE, SI, MKS, CGS, sc, dc, and rms do not have to be defined. Do not use abbreviations in the title or heads unless they are unavoidable.

The results of the assessment of the aroma of chicken liver cookies and red beans the scent of cookies can determine the deliciousness of the food itself. In many ways, the aroma becomes the main attraction in determining the taste of the food product itself; the five sense of smell more influences the aroma. In general, odours that can be received by the nose and brain are more a mixture of four kinds of odours, namely fragrant, acidic, rancid and scorched. The aromas are tastes and odours that are very subjective and difficult to measure because everyone has different sensitivity and preferences. The aroma issued by each food is different. Besides, different ways of cooking will cause different scents.

\section{The results of the assessment of the aroma of chicken liver cookies and red beans}

The scent of cookies can determine the deliciousness of the food itself. In many ways, the aroma becomes the main attraction in determining the taste of the food product itself; the five sense of smell more influences the aroma. In general, odours that can be received by the nose and brain are more a mixture of four kinds of odours, namely fragrant, acidic, rancidand scorched. The aromas are tastes and odours that are very subjective and difficult to measure because everyone has different sensitivity and preferences. The aroma issued by each food is different. Besides, different ways of cooking will cause different scents.
Figure 2. The results of the scent assessment of chicken liver and red bean cookies

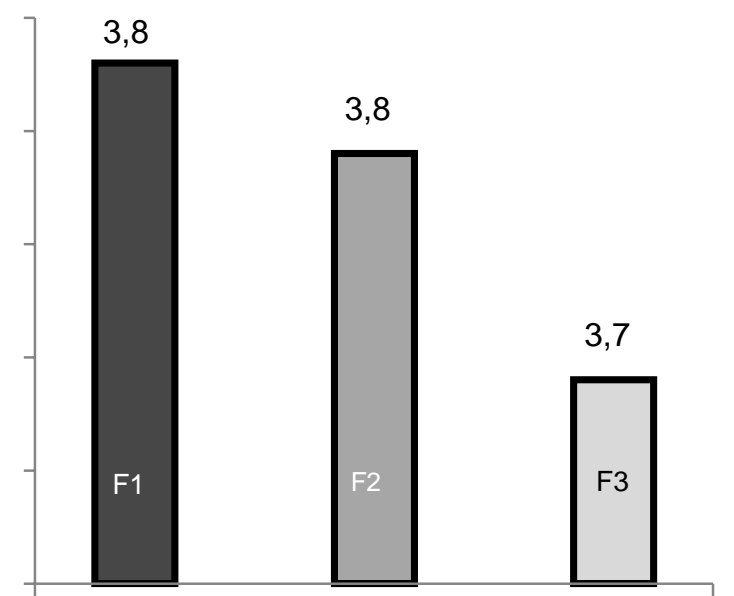

The taste is assessed by the presence of chemical stimulation responses by the taste buds (tongue), where finally the unity of interaction between the properties of the aroma, taste, and texture is the overall taste or flavour of the food being assessed. At high consumption, the taste buds will easily recognize these basic tastes. Some components that play a role in determining the taste of food are the aroma of food, spices, and food ingredients, tenderness or suppleness of food, the crispness of food, the level of maturity and temperature of the food.

Figure 3. Result of taste assessment of chicken liver and red bean cookies

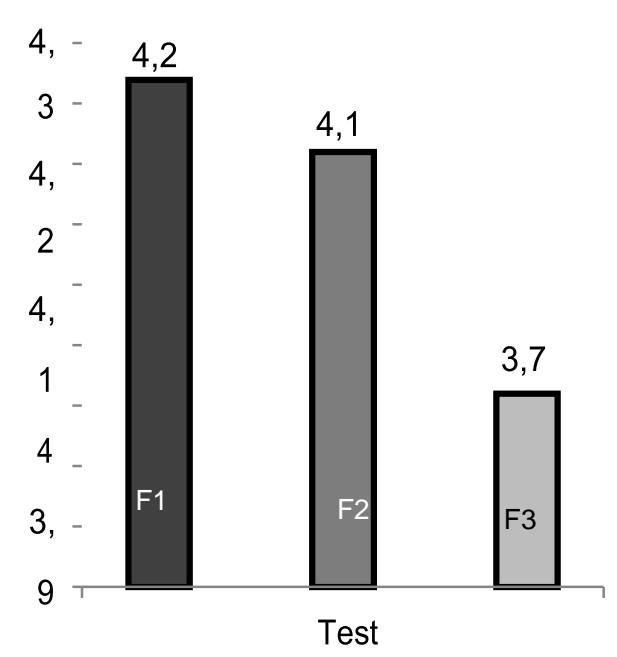


Figure 3. shows that the average value of taste is 3.72 - 4.24 which is the usual range, likes, likes. The average preference value for formula 1 gets the highest value of 4.24 formula 2 with a value of 4.12 and the lowest value in formula 3 with a value of 3.74 . Formula 1 gets the highest score on the hedonic test because of the excellent taste with the right sweet and savoury sweetness like cookies in general. The desired taste in chicken liver cookies and red beans is spicy and sweet. Among the three formulas which are the closest to the criteria is $F 1$ with an average value of 4.24 because of the small addition of chicken liver flour. Sari's research result (2017) substitution of chicken liver and mocap-arrowroot flour with a proportion of chicken liver that gets more value for flavour is lower than taste, and colour. This can be caused by the fishy smell coming from the chicken liver. This study follows research by Kiskini et al. (2007), which states that the greater the percentage of animal protein in biscuits, the flavour of the biscuits becomes unpleasant [8].

Savoury taste can be obtained from the types of foods that contain high protein or fat. The flavour most favoured by panellists is the F1 taste where cookies that get the addition of chicken liver flour have a slightly savoury salty taste that is mild. Simultaneously, cookies that get many additions to F2 and F3 chicken liver flour have a chalky taste. This is because the chicken liver flour feels chalky, but the overall taste of the cookies produced is still acceptable to panellists.

Putri's research (2012) also shows results that are in line with cookies with the addition of animal and vegetable flours not leaving too much aftertaste due to the addition of flavoured milk powder and topping with choco chips [6].

Based on the results of the test of preference for the taste of cookies, chicken liver, and red beans, most panellists really liked the taste in formula 1 which approached the savoury criteria in cookies and had a slightly chalky taste.

3. The texture assessment of chicken liver and red bean cookies.

The texture is a characteristic that can be assessed by the sense of touch. Some parts or areas such as the oral cavity, hands, and lips have a high sensitivity to touch and touch. The texture is an essential aspect of food quality, sometimes more important than smell, taste, and colour. The surface is necessary for soft foods and crispy foods. The most important characteristics to be referred to are violence, cohesiveness, and water content. Crunchiness or texture is one of the determinants of the quality of biscuits that need attention because it is closely related to consumer acceptance.

Figure 4. Results of texture assessment of chicken liver and red bean cookies.

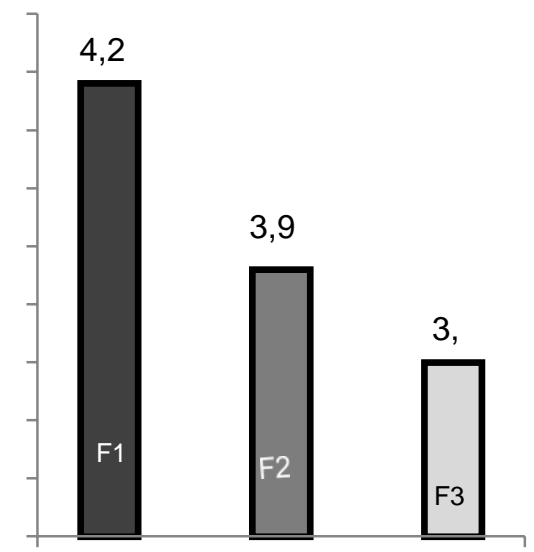

Figure 4. shows that the average texture value is 3.8 4.28 , which is the range of likes, likes, likes. The average matter of preference to the texture of the chicken liver and red bean cookies in formula 1 with a value of 4.28 . Formula 2 with a value of 3.96 and the lowest value in formula 3 with a value of 3.8 .

The texture of cookies is greatly influenced by each ingredient used. Chicken liver flour has a rather rough surface. Based on the data, it can be predicted that the addition of chicken liver flour will become coarser if the F1 treatment texture is crisper than the F2 and F3 treatments. According to Ekawati (1999) making red bean flour cookies for texture shows that there is no difference in the level of substitution. Presumably, the crisp cookies produced because of the formula of cookies consisting of high sugar and fat, but low water content. The amount of sugar and fat that causes the even distribution of the ingredients of the cookies during baking.

Based on the results of the test of preference on the texture of chicken liver and red bean cookies between the three formulas tested, F1 products were highly favoured by panellists with an average value of 4.28 with a crunchy texture. And this study is in line with Hertisa's (2012) panellists seem to like the texture of nutrient-rich cookies which are considered to have the most crispy textures compared to other cookies.

\section{Acceptability Test}

The panellist acceptance test is closely related to the level of consumer acceptance of a product. In general, the assessment mode is in the parameters rather like, like and like. 
Figure 5. The average value of chicken liver and red bean cookie formulas

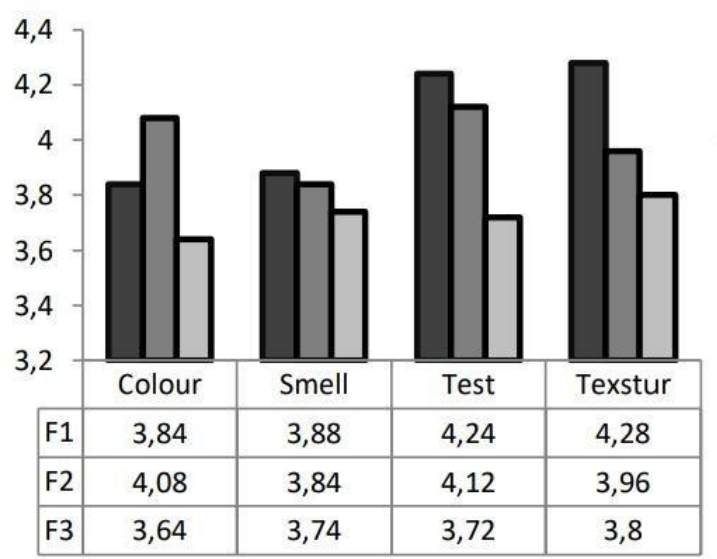

Based on Figure 5. Color of cookies on F2 gets the highest average value of 4.08 of all formulas and the lowest on F3 (3.64). The smell scoring on F1 receives the highest value of 3.88 and the most inferior formula 3 with a value of 3.74 . Results The average preference value for formula 1 gets the highest value of 4.24 formula 2 with a value of 4.12 and the lowest value in formula 3 with a value of 3.74 . In the assessment of the texture of cookies in formula 1 with a value of 4.28. Formula 2 with a value of 3.96 and the lowest value in formula 3 with a value of 3.8. Based on the average value, the result shows that formula 1 gets the highest average value or is preferred by panellists with aroma parameters (3.88), taste (4.24) and texture (4.28) and in formula 2 gets the highest average value with parameters color $(4,08)$.

\section{CONCLUSION}

Based on the results of research conducted it can be concluded as follows:

1. The best formulation of chicken liver and red bean cookies is found in formulation 1 with the addition of tapioca flour (20 g), chicken liver (10 g) and red beans $(20 \mathrm{~g})$ is the best addition amount which gives off a sweet or fishy aroma, savoury taste and crispy texture and formulation 2 with the addition of tapioca flour (20 g), chicken liver (15 g) and red beans $(15 \mathrm{~g})$ are the best additions that give a brown colour.

2. Organoleptic test results in formula 1 , formula 2 and formula 3 note that the positive panellist response can be seen from the value of the cookies mode for all formulas ranging from somewhat like, like and very like with the percentage of panellist acceptance ranging from $72 \%-85.6 \%$ including the percentage panellists' preference for colour between $(72.8 \%-81.6 \%)$, aroma $(74.4 \%-77.6 \%)$, taste $(74.4 \%-84.4 \%)$ and texture $(76 \%-85.6 \%)$. The selected products that have the highest preference score in formula 1 are aroma parameters $(77.6 \%)$, taste $(84.8 \%)$, texture $(85.6 \%)$ andformula 2 in colour parameters $(84.4 \%)$.

3. To increase the utilization of chicken liver and kidney beans in making cookies, further research with complete chemical testing is needed. Besides, various studies on the substitution of chicken liver flour and kidney beans can be done on other products.

\section{ACKNOWLEDGMENT}

The author would like to thank the Palembang Poltekkes who helped fund this research.

\section{REFERENCES}

[1] Department of Health Indonesia. Basic Health Research Report, Health Research and Development Agency. 2008.

[2] Darlan A. Fortification and Availability of Iron in SoybeanBased Food Materials Using Fortified FeSO4. Faculty of Mathematics and Natural Sciences,University of Indonesia.; 2012.

[3] Gleason G NS. An overview of the functional significance of iron deficiency. Didalam Nutritional Anemia,. ed by Klaus Kraemer \& Michael B. Zimmermann., editor. 2007. Switzerland: Sight and Life Press;

[4] WHO. Iron Deficiency Anemia : Assessment prevention and control. A Guide for Programme Managers dala WHO.Worldwide Prevalance of Anemia 1993-2005 WHO Global Database on Anemia . Ed. Benois. 2008.

[5] Berdanier CD dan ZJ. Advanced Nutrition: Macronutrients, Micronutrients and Metabolism. Boca Raton: CRC Press; 2009. 309-339, 476-482 p.

[6] Putri H. Organoleptic Test of Nutrient-Rich Cookies Formulation as2 Supplementary Food in Efforts to Prevent Anemia in Pregnant Women in Rangkap Jaya Depok. Thesis. Un. Jakarta; 2012.

[7] Zahara N. The Effect of Red Bean Flour Substitution on Cookies Quality. University. PS, editor. 2010. Padang;

[8] Kiskini S, Argiri K, Kalogeropoulos M, Komaitis M, Kostaropoulos A, Mandala I KM. Sensory characteristics and iron dialyzability of glutenfree bread fortified with iron. Food Chem. 2007;102 (1):309-16. 